\title{
Foreword to: Special Issue-Networking and Electronic Commerce Conference, Trieste, Italy, 2014
}

The field of telecommunications is a broad array of technology, people, messages, and data that must interface in increasingly complex and myriad forms. Just as the World Wide Web spawned a telecommunications revolution a generation ago bringing the world to our desktops, mobile communications revolution of the past decade has brought the world to our fingertips. In the mid-1990s, I asked noted computer scientist and founding father of the ARPANET, Dr. Leonard Kleinrock, if he envisioned what he termed "Nomadic Computing" at the time to be a reality within the next decade. He explained that he firmly believed in the ability to access any piece of information, any application, or the ability to communicate with any person from anywhere on the face of the earth would become possible within this time frame. Not only has the wireless revolution brought Kleinrock's vision to reality, it has in my opinion, surpassed his or anyone else's wildest expectations.

The interdisciplinary nature of telecommunications research brings together electrical engineers, computer scientists, information scientists, physicists and business researchers to delve into the nature of how machines, peo- ple and organizations communicate and cooperate over both time and space of varying quantities. It was in the spirit of this interdisciplinary nature that the International Conference of Networking and Electronic Commerce was held in August of 2014 in Trieste, Italy. Dr. Bezalel Gavish of Southern Methodist University in the U.S., the conference's founder, and myself hosted researchers from the U.S., Europe, South America, Africa and Asia who presented state of the art research in various facets of telecommunications and the related area of electronic commerce. From the research presented at this conference, select researchers were solicited to expand their research ideas into full manuscripts for a special journal issue. I am proud to put forth the efforts of these researchers in the Telecommunications Systems Journal.

Michael R. Bartolacci, Ph.D.

Associate Professor of Information Sciences and

Technology

Pennsylvania State University - Berks 